\title{
CITRA PEREMPUAN DALAM LAGU-LAGU DANGDUT: ANALISA FEMINISME DALAM BUDAYA POPULER
}

\author{
Hasby Ash-shidiqy \\ hasbi.assiddiqi@uinsgd.ac.id
}

\begin{abstract}
INTISARI
Pemahaman citra perempuan atau femininitas dari waktu ke waktu tidak pernah lepas dari unsur budaya yang mengikutinya. Penelitian ini menganalisa citra perempuan dalam beberapa lagu dangdut. Penelitian ini menggunakan pendekatan Feminisme dalam menganalisanya. Teori ini dipakai untuk menjelaskan: pertama, bagaimana perempuan digambarkan dalam lagu-lagu dangdut dan kedua, bagaimana budaya patriaki membentuk citra perempuan dalam kaitannya dengan norma budaya femininitas. Dari hasil analisa ditemukan bahwa terdapat enam citra perempuan, sebagai istri yang menderita, gadis lugu, penyanyi dangdut, wanita idaman lain, wanita karier dan, perempuan yang materialistis. Keenam citra tersebut terbentuk karena latar belakang budaya yang melingkupi produksi lagu-lagu tersebut adalah budaya patriaki, sehingga cara pandang terhadap perempuan tersebut menggunakan kacamata patriaki.
\end{abstract}

Kata Kunci: Dangdut, Budaya Populer, Feminisme, Feminitas, Patriaki

\begin{abstract}
Understanding of women image or femininity has never been separated from its cultural background. This study analyzes the image of women in some dangdut songs. This research uses Feminism theory. This theory is used to explain: first, how women are portrayed in the dangdut songs and second, how the patriarchal culture shapes the image of women in relation with the cultural norms of femininity. From the analysis it was found that there are six images of women, as wives who suffer, innocent girl, dangdut singer, the other woman, career women and materialistic girl. The images are formed due to the cultural background of the song production, which was by patriarchal culture.
\end{abstract}

Key Words: Dangdut, Popular Culture, Feminism, Femininity, Patriarchy

\section{A. Latar Belakang Penelitian}

\begin{tabular}{lr}
\multicolumn{2}{c}{ Pemahaman citra } \\
perempuan atau femininitas dari \\
waktu ke waktu tidak pernah lepas \\
dari unsur budaya yang \\
mengikutinya. Dahulu, seperti dalam
\end{tabular}

cerita-cerita tradisional Sunda ataupun Jawa, perempuan sering digambarkan sebagai sosok yang lemah lembut dan sepertinya tidak pantas beraktivitas di luar rumah, atau dalam cerita tradisional Barat yang berjudul Cinderella, perempuan 
digambarkan sebagai sosok yang menenati datangnya sosok lelaki pujaan; dan bahkan dikalangan masyarakat modern pun perempuan mengalami nasib yang sama, perempuan tidak memiliki kuasa terhadap namanya-kita lazim menamai seorang istri dengan nama suaminya. Dengan demikian-pada masyarakat kita, disadari ataupun tidak-perempuan tidak memiliki kuasa terhadap dirinya sendiri. Sehingga pada gilirannya, pencitraa perempuan di wilayah ini tidak akan jauh berbeda dengan apa yang terjadi di wilayah budaya popular.

Perbincangan tentang citra perempuan di wilayah budaya populer merupakan perbincangan yang mengalami banyak perdebatan. Ada yang memandang baik dan adapula yang memandang sebaliknya. Dalam wacana periklanan, misalnya citra perempuan ada yang dikesankan sebagai sosok penggoda yang mengundang hasrat lawan jenis. Iklan-iklan seperti ini biasanya iklan produk wewangian lelaki. Sebuah produk parfum bermerek Axe menampilkan perempuan dengan tipe seperti ini. Di sini perermpuan ditampilkan sebagai sosok yang tersubordinasi oleh lelaki. Di sisi lain, ada pula iklan yang manampilkan perempuan sebagai sosok keibuan atau ibu rumahtangga yang pintar mengurus rumah. Namun, pencitraan seperti ini lagilagi masih menyimpan banyak persoalan, karena di sini sosok perempuan masih dikesankan sebagai sosok yang tersubordinasi di wilayah patriakal.

Di wilayah budaya populer yang lainnya seperti sastra populer, pencitraan perempuan juga mengalami hal yang kurang lebih sama dengan apa yang ada di iklan dan televisi. Fiksi popular yang bergenre adventure misalnya seringkali menampilkan sosok perempuan sebagai pelengkap bagi hero (aki-laki). Fiksi popular karangan Rick Riordan yang berjudul Percy Jackson and the Lighting Thief menggambarkan bagaimana perempuan dianggap sebagai pemeran pembantu semata. Novel ini menceritakan perjalanan tiga anak remaja yakni Percy, Annabelle, dan Groofer. Percy merupakan tokoh utama dalam pencariannya membuktikan bahwa ia bukan pencuri petir milik Zeus, Annabelle dan Groofer mendampingi Percy dalam pencarian tersebut. Tokoh Annabelle di dalam novel ini dikarakterisasikan sebagai sosok perempuan yang mendampingi Percy. Dari sini kita bisa melihat bagaimana perempuan masih dicitrakan hanya sebagai sosok pendamping laki-laki, sosok yang melengkapi laki-laki. Dengan demikian, sepertinya, kehadiran perempuan akan ada setelah keberadaan laki-laki. Jika laki-laki tidak ada maka perempuanpun tidak ada. Hal yang senada juga terdapat di novel adventure lainnya seperti novel best seller serial Harry Potter karya J.K Rowling. Di sini tokoh perempuan Hermione yang meskipun dikarakterisasikan sebagai tokoh yang pintar, lagi-lagi, ditampilkan hanya sebagai tokoh pendamping bagi Harry Potter. Kepintaran Hermione ternyata tidak bisa mengalahkan dominasi laki-laki yang diwakili oleh Harry Potter. Padahal penulis serial novel ini dalah J.K Rowling yang merupakan perempuan. Hal yang sama juga akan kita jumpai di film yang bergenre sama. Film Pirate of Caribbean, 
misalnya menampilkan sosok perempuan yang kurang lebih sama, sebagai pelengkap bagi laki-laki tokoh utama. Di film Pirate of Caribbean yang keempat sosok perempuan bahkan ditinggalkan begitu saja oleh tokoh utamanya. Dia dibuang ke sebuah pulau dan si tokoh utama meninggalkannya begitu saja. Di novel populer lain yang bergenre romance, yang penulisannya dihususkan untuk para pembaca perempuan, perempuan digambarkan sebagai sosok perempuan yang mendamba lelaki, sosok perempuan yang berharap ada lelaki yang datang membawanya. Genre fiksi popular dengan formula Cinderella misalnya, perempuan digambarkan sebagai sosok yang pasif yang berdiam diri dan berharap ada sosok pangeran datang membawanya pergi untuk dinikahi (Cawelti, 1976: 42)

Penelitian ini akan mengkaji bagaimana perempuan ditampilkan dalam lagu-lagu dangdut. Dan Bagaimana budaya patriaki membentuk citra perempuan dalam kaitannya dengan norma budaya femininitas?

\section{B. Manfaat Penelitian}

Penelitian ini akan memiliki manfaat baik secara teoritis maupun secara praksis. Pemaparan tentang manfaat penelitian ini akan dipaparkan sebagai berikut. Secara teoritis manfaatn penelitian citra perempuan dalam lagu-lagu dangdut ini adalah semakin berkembangnya penelitian yang menggunakan analisa sastra popular, karena di wilayah sastra secara garis besar ada dua kategori sastra; yakni sastra adiluhung atau canon dan sastra popular. Secara teoritis, penelitian kedua sastra tersebut sangat berbeda walaupun sama-sama mengkaji teks. Di dalam penelitian ini, peneliti manggunakan analisa sastra popular untuk mengkaji lagu-lagu dangdut tersebut. Sehingga manfaat yang nanti didapat salahsatunya adalah keberagaman kajian wilayah popular terutama sastra popular, dimana kajian lirik dangdut merupakan salah satu kajian dari sastra popular.

\section{Teori}

Feminism berasal dari bahasa Latin Femina yang berarti perempuan. Gerakan ini mulanya muncul pada awal abad 20 yang dipelopori oleh seorang sastrawan perempuan bernama Virginia Wolf yang mempertanyakan posisi perempuan diantara kaum laki-laki dalam bukunya yang berjudul A Room of One's Own yang terbit pada tahun 1929. ( Ratna, 2004, 183). Dalam bukunya tersebut Wolf menuntut dihadirkanya ruang untuk diri pribadi perempuan. Tulisannya tersebut terinspirasi dari kunjungannya ke sebuah universitas dan British Museum di Inggris. Ia kemudian menyimpulkan bahwa bagi perempuan tidak ada ruang untuk berkarya dan mengeekspresikan dirinya sendiri. "a woman must have money and a room of her own if she is to write fiction; and that, as you will see, leaves the great problem of the true nature of woman and the true nature of fiction unsolved" (Wolf, 1977:7-8). Seorang perempuan harus mempunyai uang dan ruang bagi dirinya sendiri untuk menulis fiksi, dan itu membiarkan hal besar tentang sifat perempuan dan sifat fiksi tidak terpecahkan. Dengan sedikit saja uang bisa jadi perempuan bisa menghirup kebebasan dari rasa tertekan: tertekan karena pada saat itu lebih banyak para pengajar pria 
yang mapan, serta tekan karena posisi perempua pada saat itu masih belum seimbang. Menurut Venker dan SchLafly, Feminisme sendiri adalah "a branch of socialism, or collectivism, which draws on a sociopolitical movement that attempts to create a stateless society in which policy decisions are pursued in the (supposed) best interest of society(2010: 28). Feminisme merupakan cabang dari sosialisme, atau kolektivisme, yang mengacu pada sebuah gerakan sosial politik yang mencoba untuk menciptakan masyarakat tanpa negara di mana keputusan kebijakan yang ditempuh dalam (seharusnya) kepentingan masyarakat.

Dalam kaitannya dengan relasi perempuan dan laki-laki dikaitkan dengan teori feminism, Ratna, mengutip Selden, menawarkan gagasan bahwa perlunya dibedakan antara male-female (bahasa Inggris yang berarti lelaki dan perempuan) dan masculine-feminine (Bahasa Inggris yang berarti sama yakni lakilaki dan perempuan). Male-female berada dalam konteks biologis, sehingga dua kata ini berkonotasi membedakan tubuh laki-laki dan perempuan secara fisik. Sementara masculine-feminine berada dalam konteks budaya dan psikologis(2004: 184). Sehingga, lanjut Ratna, tujuan munculnya gerakan feminism adalah keseimbangan dan interelasi gender. Dengan demikian feminis adalah "gerakan kaum wanita untuk menolak segala sesuatu yang dimarginalisasikan,

disubordinasikan, dan diremdahkan oleh kebudayaan dominan, baik dalam bidang politik dan ekonomi maupu kehidupan social pada umumnya" (Ratna, 2004: 1984). Hal yang sama juga dikatakan oleh Lois
Tyson, ia menjelaskan bahwa tujuan gerakan feminism adalah

to change the world by promoting women's equality. Thus, all feminist activity can be seen as a form of activism, although the word is usually applied to feminist activity that directly promotes social change through political activity such as public demonstration, boycotts, voter education and registration, the provision of holiness for rape victims and shelters for abused women, and the like. (2006: 92)

Jelasnya, gerakan feminism hadir untuk mengubah pandangan dunia dengan mempromosikan kesetaraan gender. Sehingga, dengan demikian, kegiatan kaum feminis bisa dilihat dalam bentuk gerakangerakan, termasuk demonstrasi, aksi boikot, pendidikan pemilu, membuka jaringan telepon pengaduan korban perkosaan, dan lainnya.

Di wilayah kesusasteraan, feminism dikaitkan dengan cara memahami karya sastra baik yang berkaitan dengan proses penciptaan karya maupun pembacaan karya, proses produksi dan resepsi. Feminism mempertanyakan dominasi laki-laki atas perempuan. Mengapa perempuan selama ini tidak bisa setara dengan kaum laki-laki, dan mengapa perempuan seolah tidak punya ruang untuk bersuara. Kritik sasatra feminism, yang digunakan dalam kajian sastra yang didominasi kaum laki-laki, merupakan kritik yang dominan dilakukan di Amerika pada awal tahun 1970-an (Tyson, 2006: 117). Dan cara kerja kritik feminism ini 
adalah "requires reading 'against the grain' of the text's apparent intention", melawan arus dari apa yang biasanya jelas tertera di dalam teks. Hal ini dikarenakan "patriarchal literature is usually unconscious of the sexist ideology it promotes, or perhaps more precisely, patriarchal literature sees nothing wrong with its own sexism"'(Tyson, 2006: 118). Sastra patriaki biasanya tidak sadar dengan gagasan seksis yang dikandungnya, atau lebih tepatnya, sastra patriaki tidak menganggap ada yang salah dengan permasalahan gender.

Lebih lanjut Ratna mengemukakan bahwa sesuai dengan latar belakang kelahirannya, yakni sebagai gerakan politik, social, dan ekonomi, "analisa feminis dengan demikian termasuk penelitian multidisiplin" yang melibatkan berbagai disiplin ilmu pengetahuan. Dalam kaitannya dengan permasalahan kesusasteraan, analisis feminis akan berkutat pada: tradisi tulis perempuan, pengarang perempuan, pembaca perempuan, ciri-diri khas bahasa perempuan, tokoh-tokoh perempuan, dan kaitan novel popular dan perempuan (Ratna, 2004: 188).

Dalam budaya popular, kajian feminis bisa dilacak dari tahun 1950an. Kritik feminism di wilayah budaya populer, menurut Strinati, ditenggarai sangat dipengaruni oleh gerakan perempuan pada tahun 1950an. Kritikus feminis mulai mempertanyakan "how and why popular culture and the mass media have dealt with women and their representation in an unfair, unjust and exploitative maner, within the context of more general framework of gender inequality and oppression" (Strinati, 1999: 178). Para kritikus ini mempertanyakan mengapa dan bagaimana budaya popular dan media masa berurusan dengan masalah perempuan dan representasirepresentasinya dengan cara yang tidak adil, tidak seimbang dan eksploitatif, dalam konteks ketidaksetaraan gender dan penindasan terhadap perempuan.

Perempuan, menurut Strinati, dalam budaya popular mengalami "symbolic annihilation of women", yakni secara simbolis ditiadakan. Kaum perempuan dikesampingkan, diremehkan, dan dimarjinalkan dalam bentuk stereotiop yang didasarkan pada daya tarik seksual maupun pekerjaan rumah tangga.

Cultural representations of women in the mass media are conceived of as working to support and continue the prevailing sexual division of labour, and orthodox conceptions of femininity and masculinity. The 'symbolic annihilation of women' practiced by mass media serves to confirm that the roles of wife, mother and housewife, etc., are fate of women in a particular society. (Strinati, 1999: 181)

Kutipan di atas menjelaskan kepada kita bahwa, berbagai penggambaran perempuan di media masa dianggap mendukung dan meneruskan pembagian kerja secara gender, sebagaimana yang sudah umum diterima di masyarakat maupun pemahaman tentang femininitas dan maskulinitas secara tradisional. Peniadaan perempuan secara simbolis yang diusung oleh media masa, yang berfungsi untuk menegaskan peran istri, ibu, dan ibu rumah tangga, merupakan takdir perempuan dalam sebuah masyarakat 
patriakal. Sehingga tidak akan tampak peran perempuan sebagai menteri, direktur, atau pekerjaan lain yang biasanya merupakan pekerjaan "milik" kaum laki-laki.

Singkatnya, kajian feminis akan mempermasla1,5 cmhkan citra perempuan dalm sebuah karya, tradisi tulis perempuan, pengarang perempuan, pembaca perempuan, ciri-diri khas bahasa perempuan, tokoh-tokoh perempuan, dan kaitan novel popular dan perempuan. Sementara cara kerjanya adalah dengan pembacaan melawan arus dari apa yang biasanya jelas tertera di dalam teks.

\section{Metode Penelitian}

Penelitian ini akan menggunakan pendekatan feminism, hal ini akan berguna karena objek kajian penletiaian ini adalah tentang citra perempuan dalam sebuah teks. Pendekatan ini seperti yang dikatakan oleh Storey, bisa memosisikan sejauhmana perempuan hadir dalam wilayah-wilayah budaya popular (2001: 114-115). Hal yang senada juga dikatakan oleh Strinati. Ia menjelaskan bahwa analisa yang mencakup peran perempuan atau gambaran perempuan dalam sebuah teks bisa ditelusuri dengan pendekatan feminism (1995: 178180)

Penelitian ini adalah penelitian dengan model kajian sastra populer. Sehingga lagu-lagu yang dipilih adalah lagu-lagu yang popular di kalangan masyarakat. Pemilihan lagu-lagu ini adalah dengan melihat kepopuleran lagu tersebut. Salah satu Indikator kepopulerannya adalah seberapa sering lagu-lagu tersebut dilihat di Youtube. Pemilihan situs Youtube menjadi penting karena situs ini bisa menjadi indikasi kepopuleran sebuah lagu. Karena jika lagu ini popular sudah bisa dikatakan pasti banyak orang yang akan melihat video klipnya di Youtube atau bahkan akan banyak orang yang akan merilis ulang dalam bentuk cover lagu tersebut.

\section{E. Temuan dan Pembahasan}

1. Citra Perempuan Dalam Lagu Dangdut

Dari hasil analisa terhadap beberapa lagu dangdut, didapat beberapa citra perempuan. Terdapat beberapa citra perempuan di dalam lagu-lagu yang di teliti. Setidaknya ada enam citra yang ditemukan dalam penelitian ini keenam citra itu adalah: citra perempuan sebagai istri yang menderita, citra perempuan sebagai penyanyi dangdut, citra perempuan sebagai perempuan yang materialistis, citra perempuan sebagai gadis yang lugu, citra perempuan sebagai wanita idaman lain, dan terahir citra perempuan sebagai wanita karier.

Di wilayah kebudayaan yang masih menganut faham patriaki, seperti Indonesia, keberadaan istri masih dianggap sebagi pelengkap bagi suaminya. Di sini istri kemudian harus tunduk dan patuh kepada suaminya, jika tidak diizinkan, istri tidak diperkenankan bekerja di luar rumah. "After marriage, a woman leaves her parents'household to live in her husband's family household and becomes part of it if she is marrying endogamously (Nurmila, 2009: 23). Sebagai seorang istri, perempuan akan meninggalkan rumah orangtuanya dan menetap serta mengabdi kepada suaminya. Ketundukan kepada suami menjadi kewajiban di wilayah bidaya yang masih kental budaya patriakinya, 
seperti di Indonesia. Di dalam lagu dangdut yang berjudul "Payung Hitam" yang diciptakan oleh Puji M Mirani dan dinyanyikan oleh Iis Dahlia, citra perempuan dijelaskan sebagai seorang istru yang menderita karena perilaku suaminya yang menduakan cintanya. Istri dalam lagu ini tidak rela cintanya dimadu. Walaupun budaya di Indonesia, yang dilatarbelakangi oleh agama Islam, memperbolehkan poligami, namun kejadian ini tetap saja akan menyakitkan bagi istri. Penderitaan yang dialami oleh istri manakala mendengar suaminya tergoda bahkan menikah dengan perempuan lain menjadi bencana. Ia menganggap kejadian ini sebagai bencana, sehingga dari kata 'bencana' kita bisa menarik kesimpulan bahwa apa yang didertiuka oleh istri ini adalah penderitaan yang sangat besar.

Citra perempuan sebagai penyanyi lagu dangdut bisa ditemukan pada lagu yang berjudul "Goyang Mujaer" karangan Dadan Indriana, dan dinyanyikan ulang oleh Ayu Ting Ting pada tahun 2014. Lagu ini bercerita tentang seorang lelaki bernama Mustofa yang sakit hati ditinggal oleh kekasihnya. Ia lalu mencari pelarian dengan bergoyang dan berkencan dengan biduan dangdut. Dalam lagu ini citra perempuan digambarkan sebagai penyanyi dangdut yang menggoda lelaki. Godaan yang diberikan perempuan penyanyi dangdut ini adalah godaan yang menjurus seksual.

Citra perempuan di dalam lagu dangdut juga menampilkan citra perempuan yang materialistis. Pandangan ini cukup negative. Karena budaya di Indonesia akan memandang mirip perempuan yang dicap materialistis. Perempuan materialistis atau sering disingkat permpuan matre atau dalam bahasa yang tidak formal disebut juga cewek matre. Tipe perempuan seperti ini adalah perempuan yang tergila-gila sama harta. ia akan menyukai lelaki yang memiliki kekayaan. Di dalam lagu dangdut yang berjudul "Berondong Tua" yang diciptakan oleh Endang Raes dan dinyanyikan oleh penyanyi Siti Badriah, citra perempuan ditampilkan sebagai sosok perempuan materialistis.

Pencitraan lain adalah citra perempuan sebagai gadis lugu. Citra ini dapat ditemukan dalam lagu dangdut yang berjudul "Gembala Cinta" karangan Ashraf. Citra perempuan sebagai wanita idaman lain, atau perempuan yang dianggap merebut suami orang lain terdapat dalam lagu yang berjudul "Minyak Wangi karya Dadan Indriana dan dinyanyikan oleh Ayu Ting Ting, "S M S" karya Yanto Sari dan dinyanyikan oleh Ria Amelia, "Suamiku Kawin Lagi" karya Endang Raes dan dinyanyikan oleh Siti Badriah,'Tersisih" karya H.Ukat dan dinyanyikan oleh Rita Sugiarto, "Dua Kursi" karya Udi S bersama Muchlas Ade Putra dan dinyanyikan oleh Rita Sugiarto, dan terahir lagu berjudul "Payung Hitam" karya Puji M Mirani dan dinyanyikan oleh Iis Dahlia.

Dari beberapa lagu dangdut yang dianalisa, ada satu lagu dangdut yang menampilkan citra perempuan sebagai wanita karier. Sosok perempuan ini terdapat dalam lagu yang berjudul "Punya Abang" karangan Don Kinol dan dinyanyikan oleh Selvi Kitty. Dalam lagu ini perempuan digambarkan sebagi perempuan modern yang sudah mampu bekerja di luar rumah. 
2. Budaya Patriaki Membentuk Citra Perempuan Dalam Kaitannya Dengan Norma Budaya Femininitas

Lagu dangdut yang berjudul "Minyak Wangi" ini menggambarkan relasi antara lakilaki dan perempuan, dimana sang perempuan menduga si lelaki ada main dengan perempuan lain. Relasi permpuan dan lelaki di dalam lirik ini menygisyaratkan bahwa perempuan tidak mudah menggapai dan mempertahankan cintanya. Disini Nampak bahwa perempuan mudah dipermainkan oleh laki-laki, seolah tidak ada komunikasi antara lelaki dan perempuan dalam lagu ini. Perempuan sepertinya dianggap tidak ada, karena tiba-tiba saja si lelaki keluar rumah mencari cinta yang lain tanpa mempedulikan sang perempuan dalam lagi ini. Perempuan dalam lagu ini digambarkan sebagai sosok perempuan rumahan, yang akan merasa berdosa jika mempertanyakan keberadaan lakilaki. Penggambaran perempuan yang seperti ini merupakan pola penggambaran perempuan yang mencerminkan bahwa system patriaki masih kental dalam budaya Indonesia. Perempuan akan merasa tabu jika berinisiasi mengajak lakilaki bercinta, perempuan masih merasa tabu jika duluan menyatakan cinta kepada laki-laki. Perempuan lazimnya, dalam budaya patriaki di Indonesia, menunggu dilamar, melayani suami, berdiam di rumah sambil menunggu datangnya suami.

Dalam lagu Geboy Mujaer, kita bisa melihat bahwa perempuan menjadi sosok atau "barang" yang diangap mampu meredam kekecewaan lelaki. Ketika si lelaki merasa kecewa, ia mencari hiburan dengan "membeli" perempuan. Bahkan si aku liris, yang menurut saya adalah representasi perempuan, menawarkan jasa untuk mengobati kekecewaan si lelaki dengan goyang mujaer.

Apa yang terjadi dalam lagu "bang Jono" masih menyiratkan budaya patriaki yang kental, dimana perempuan maih pasif tinggal di rumah mengurus rumah dan anak, sementara si lelaki ke luar rumah untuk mencari nafkah. Relasi perempuan dan lelaki yang seperti ini mengindikasikan kuatnya budaya patriaki di Indonesia, yang merupakan rumah bagi lagu-lagu dangdut. Sebagaimana lazimnya budaya patriaki, dalam lagu inipun perempuan melakukan pekerjaanpekerjaan domestik, seperti mengurus anak dan mengurus rumah.

\section{F. Simpulan}

Dari hasil analisa dan pembahasan tentang citra perempuan dalam beberapa lagu dangdut dapat ditemukan bahwa terdapat enam citra perempuan. Penggambaran atau citra ini didapat berdasarkan makna langsung ataupun makna kiasan. Keenam citra tersebut adalah: citra perempuan sebagai istri yang menderita, citra perempuan sebagai penyanyi dangdut, citra perempuan sebagai perempuan yang materialistis, citra perempuan sebagai gadis yang lugu, citra perempuan sebagai wanita idaman lain, dan terahir citra perempuan sebagai wanita karier.

Semua lagu yang dianalisa menggambarkan perempuan yang dalam kehidupannya masih terkungkung oleh adat atau budaya patriaki. Budaya ini sangat kental terasa dengan menampilkan 
perempuan seakan-akan perempuan hanyalah pendamping bagi laki-laki saja. Cara pandang seperti ini misalnya ditemukan dalam lagu yang berjudol "Goyang Mujair" dalam lagu ini, relasi perempuan dan lakilaki menjelaskan bahwa perempuan seolah hanya menjadi mahluk pendamping buat laki-laki. Cara mengobati lelaki yang sedang kecewa dalam lagu ini terkesan seksis dan bernada seksual. Di sini seolah perempuan digambarkan sebagai obat penghibur bagi lelaki yang sedang kecewa. Perempuan disini hanya ditinjolkan sisi fisiknya saja, tidak ditampilkan sisi kepintaran atau psikisnya. Lagi-lagi cantik dan tubuh perempuan menjadi daya tarik bagi laki-laki.

\section{Daftar Pustaka}

Anggraina, Gina, "Representasi Perempuan Dalam Lirik Lagu Dangdut Kontemporer", 7 Juli 2015.

http://core.ac.uk/download/pdf/ 11735230.pdf

Cawelti, John, G, Adventure, Mystery, and Romance, Chicago: The University of Cichago Press, 1977.

Nurmila, Nina, Women, Islam, and Everyday Life: Renegotiating Polygamy in Indonesia, New York: Routledge, 2009.

Portal Sejarah, 3 Juli 2015. http://www.portalsejarah.com/s ejarah-dan-perkembanganmusik-dangdut-diindonesia.html

Pusat Pengembangan Koleksi dan Pengolahan Bahan Pustaka, 3 Juli 2015. http://pusbangkol.perpusnas.go .id/resensi-1.html

Ratna, Nyoman Kutha, Teori, Metode, dan Teknik Penelitian
Sastra, Jogjakarta: Pustaka Pelajar, 2004.

Rowling, J.K., Harry Potter and the Sorcerer's Stone, London: Bloomsbury, 2010.

Riordan, Rick, Percy Jackson and the Lightning Thief, London: Puffin Books, 2005.

Ruswandie, 3 Juli 2015. http://purwandie.heck.in/asalmula-dan-sejarah-aliran-musikdangd.xhtml

Safitri, Fradina Dwi, "Representasi Citra Perempuan Dalam Iklan Televisi (Analisa Semiotika Representasi Perempuan dalam Iklan WRP Diet To Go DI Televisi Swasta Medan). 7 Juli 2015.

http://repository.usu.ac.id/bitstr eam/123456789/38192/7/Cove r.pdf

Strinati, Dominic, An Introduction to Theories of Popular Culture, New York: Routledge, 1999.

Storey, John: Cultural Theory and Popular Culture: an Introduction, Edinburgh: Pearson Education Limited, 2001.

Tyson, Lois, Critical Theory Today: A User-Friendly Guide, $2^{\text {nd }}$ edition, New York: Routledge, 2006.

Venker, Suzanne dan Phyllis SchLafly, The Flipside of Feminism: What Smart Women Know, and Men Can't Say, Washington D.C: Word Net Daily, 2010.

Wolf, Virginia, A Room of One's Own, London: Grafton, 1977. 
Jurnal al-Tsaqafa Volume 13, No. 01, Januari 2016

8 